\title{
EDITORIAL
}

\section{neuroRAD 2020 Virtual}

\section{Horst Urbach ${ }^{1}$}

(c) Springer-Verlag GmbH Germany, part of Springer Nature 2020

Due to the COVID-19 pandemic the proposed motto of our annual congress "Neue Arbeitswelten"-How do we work in future? becomes realistic earlier than expected.

The neuroRAD 2020 goes virtual on 8 October and 9 October 2020 (11:00-19:00) and by offering new formats, such as live streaming, video podcasts live and on demand, moderator discussions, interventional and diagnostic video cases, TED votings, and others, we expect an ever deeper learning success.

Selected abstracts can be presented as short video podcasts (power pitches) with the presenter being online, able to receive questions in the chat, and to answer them after the podcast is finished. Accepted abstracts can be presented as ePosters and all abstracts will be available in a supplement of Clinical Neuroradiology.

Thematically, we will cover many important areas from diagnostic and interventional neuroradiology (neuro-oncology, stroke, MS diagnostics ...) presented by experienced speakers. With Fit für den Facharzt Neuroradiologie (Fit for the specialist in neuroradiology) we also offer a for- mat for resident doctors and of course we will also approach COVID-19 from the perspective of neuroradiology with current lectures.

Our industrial partners are allocated to present their products in lunchtime sessions and to use other formats by which they enhance our familiarity with them.

A CME accreditation is applied for and participation fees will be adapted.

We appreciate your continuous support for our profession and neuroRAD 2020 virtual, which will be organized in close collaboration with KUKM GmbH.

For further information please visit www.neurorad.de

Kind regards

Prof. Dr. Horst Urbach

President DGNR

Conflict of interest H. Urbach declares that he has no competing interests.
Horst Urbach

horst.urbach@uniklinik-freiburg.de

1 Klinik für Neuroradiologie, Universitätsklinikum Freiburg, Freiburg, Germany 